\title{
Pengaruh Latihan Run Through Rest Ratio 1:5 Dan Latihan Run Through Rest Ratio 1:8 Terhadap Prestasi Lari Sprint 100 Meter Pada Siswa SMP Islam Montong Kubur Tahun Pelajaran 2016/2017
}

\author{
Muhhammad Ridwan Lubis, Arif Yanuar Musrifin \\ Pendidikan Olahraga dan Kesehatan, FPOK IKIP Mataram \\ Email: tabis_one@yahoo.com
}

\begin{abstract}
The students of SMP Islam Montong Kubur always suffered defeat on the 100 meters sprint due to the lack of speed. This study aims to determine the Effect of Run Through Rest Ratio 1: 5 training and Run Through Rest Ratio 1: 8 training toward the achievement of 100 Meters Sprint on students of SMP Islam Montong Kubur in 2016/2017 academic year. The research design used experimental method to find the influence among 3 variables in one unity that allows the occurrence of influence, and to review the factor influencing in certain data. The Instrument in the implementation of this research is a pre-test of 100 meters sprint followed by run through rest ratio 1: 5 and run through rest ratio 1: 8 training, and finally carry out the post-test of 100 meters sprint. In this research, the method used to obtain the data is observation, documentation, and performance test. The population is the students of SMP Islam Montong Kubur and the sampling technique used cluster random sampling technique. The data analysis method used statistical analysis using T-Test formula as test of research hypothesis. The results of the analysis resulted t-score $>$ t-table i.e. 6.915 $>2.093$ at 5\% significance level. It can be concluded that there is Effect of Run Through Rest Ratio 1: 5 training and Run Through Rest Ratio 1: 8 training toward the achievement of 100 Meters Sprint on students of SMP Islam Montong Kubur in 2016/2017 academic year.
\end{abstract}

Kata Kunci : Latihan Run Through Rest Ratio 1:5, Latihan Run Through Rest Ratio 1:8, Prestasi Lari Sprint 100 Meter

\section{PENDAHULUAN}

Olahraga didefinisikan sebagai segala aktivitas fisik yang dilakukan dengan sengaja dan sistematis untuk mendorong, membina, dan mengembangkan potensi jasmani, rohani dan sosial (Maksum, 2009:04). Sedangkan menurut Made Pramono (2003), olahraga adalah aktivitas yang memiliki akar eksistensi ontologis sangat alami, yang dapat diamati sejak bayi dalam kandungan sampai dengan bentuk-bentuk gerakan terlatih.

Jadi olahraga adalah segala bentuk aktifitas fisik yang dilakukan dengan sengaja dan sistematis baik dalam bentuk permainan atau gerakan-gerakan yang terlatih yang bertujuan untuk mengembangkan kesegaran jasmani, rohani dan sosial untuk diri sendiri, orang lain dan alam sekitar. Atletik merupakan cabang olahraga yang mempunyai peran penting untuk menunjang perkembangan gerak anak ke arah gerakan cabang olahraga atletik. Hal ini sesuai pendapat Aip Syarifuddin (1992 :18) bahwa, "pembentukan gerak dasar khususnya pembentukan gerak dasar atletik adalah suatu dorongan dalam usaha mengalihkan bentukbentuk gerakan yang telah dimiliki anak sebelum memasuki sekolah menjadi bentukbentuk gerakan dasar yang mengarah pada gerakan dasar atletik. Dalam Olahraga Atletik yang dipertandingkan dibagi kedalam 3 (tiga) macam diantaranya :

a. Lari

- Lari Jarak Pendek : putra: 100 m, 200 m, dan $400 \mathrm{~m}$ dan putri; $100 \mathrm{~m}, 200 \mathrm{~m}$, dan $400 \mathrm{~m}$

- Lari Jarak Menengah : Putra : $800 \mathrm{~m}$, $1500 \mathrm{~m}$, dan $3000 \mathrm{~m}$ (special Chose), Putri: 800 m, 1500 m, dan 3000 m

- Lari Jarak Jauh, Putra dan Putri 5000 dan $10000 \mathrm{~m}$.

- Lari Estafet

- Lari Gawang

- Lari Marathon, Putra/Putri 42.195 m.

b. Lompat yaitu lompat tinggi, lompat jauh, lompat galah, lompat jangkit.

c. Lempar, Dalam atletik ada dua jenis nomor lempar yang dipertandingkan diantaranya lempar lembing dan lempar cakram. 
Lari cepat 100 meter atau sprint merupakan salah satu nomor bergengsi dalam cabang olahraga atletik. Lari cepat 100 meter merupakan gerakan lari yang dilakukan dengan kecepatan penuh dari garis start sampai garis finish. Berdasarkan Kurikulum Tingkat Satuan Pendidikan (KTSP) SMP bahwa, lari cepat 100 meter merupakan salah satu nomer lari jarak pendek yang harus diberikan pada siswa tingkat SMP. Upaya meningkatkan kemampuan lari cepat 100 meter siswa di sekolah dibutuhkan latihan yang sistematis dan kontinyu. Dalam masalah ini peneliti memilih salah satu metode latihan run through.

Latihan Run Through adalah termasuk dalam jenis latihan plyometric. Dalam latihan plyometric dianggap sebagai salah satu cara latihan yang paling efektif untuk meningkatkan daya ledak otot, baik pada pelari jarak pendek (Nala,1998 : 59).

Berdasarkan latar belakang diatas itulah yang mendorong penelitian ini dilakukan, untuk lebih memfokuskan diri pada cabang olahraga lari sprint 100 meter. Dan berdasarkan uraian tersebut diatas, maka penulis bermaksud melakukan penelitian tentang "Pengaruh Latihan Run through Rest Ratio 1: 5 Dan Latihan Run Through Rest Ratio 1 : 8 Terhadap Prestasi Lari Sprint 100 Meter Pada Siswa SMP Islam Montong Kubur Tahun Pelajaran 2016/2017”.

\section{METODE PENELITIAN}

Penelitian ini menggunakan jenis penelitian eksperimen yaitu penelitian dilakukan secara ketat untuk mengetahui hubungan sebab akibat diantara variablevariabel (Maksum, 2008:10).salah satu ciri utama dari penelitian eksperimen adalah adanya perlakuan (treatment) yang dikenakan pada subyek atau obyek penelitian. Kuantitatif adalah suatu penelitian dicirikan oleh pengujian hipotesis dan digunakannya instrument tes yang standar (Maksum, 2008:10). Dengan desain penelitian Two Groups Pretest-Posttest Design

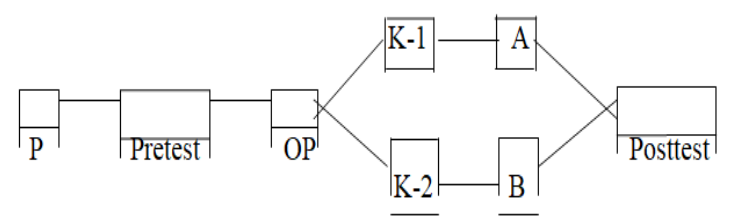

Gambar. 3.1. desain Penelitian (Sugiyono, 2007: 32)
Keterangan :

P : Populasi penelitian

Pretest : Tes awal kecepatan lari (lari sprint 100 meter)

OP : Ordinal pairing

K-1 : Kelompok eksperimen 1

K-2 : Kelompok eksperimen 2

A : Latihan run through rest ratio $1: 5$

B : Latihan run through rest ratio $1: 8$

Posttest : Tes akhir kecepatan lari (lari sprint 100 meter)

Dalam penelitian ini populasi adalah sekumpulan dari individu sejenis yang menempati suatu ruangan dan waktu tertentu (Suharsimi, 2013:173). Jadi populasi yang digunakan dalam penelitian ini adalah siswa SMP Islam Montong kubur dengan jumlah 110 siswa. Sampel adalah sebagian atau wakil dari populasi yang diteliti (Arikunto, 2013:174). Tehnik sampel yang digunakan adalah claster random sampling yaitu sampel yang dipilih secara kelompok yang kemudian diundi secara acak, sampel yang digunakan dalam penelitian ini adalah kelas VIII B.

\section{HASIL PENELITIAN}

1. Tabel kerja latihan run through rest ratio 1:5 dan latihan run through rest ratio 1:8

\begin{tabular}{|c|l|c|c|c|c|}
\hline NO & \multicolumn{1}{|c|}{ NAMA } & XI & XII & $\begin{array}{c}\text { D } \\
\text { (XII-XI) }\end{array}$ & D $^{\mathbf{2}}$ \\
\hline$(1)$ & \multicolumn{1}{|c}{$(2)$} & $(3)$ & $(4)$ & $(5)$ & $(6)$ \\
\hline 1 & Muh. Ibrahim & 292 & 305 & 13 & 169 \\
\hline 2 & M. Miskan Ariadi & 260 & 282 & 22 & 484 \\
\hline 3 & Ahmad Nopi Irawan & 260 & 282 & 22 & 484 \\
\hline 4 & M. Khaerul Hafiz Alfarobi & 210 & 230 & 20 & 400 \\
\hline 5 & M. Hidayatullah & 200 & 210 & 10 & 100 \\
\hline 6 & M. Irwan & 94 & 109 & 15 & 225 \\
\hline 7 & Bq. Komari Hadini & 82 & 88 & 6 & 36 \\
\hline 8 & Yulia Safitri & 72 & 82 & 10 & 100 \\
\hline 9 & Nuraini & 62 & 67 & 5 & 25 \\
\hline 10 & Ita Novianti & 19 & 30 & 11 & 121 \\
\hline 11 & Ardian rohman & 272 & 282 & 10 & 100 \\
\hline 12 & Dedi Kurniawan & 272 & 282 & 10 & 100 \\
\hline 13 & Tomi Amzani & 260 & 272 & 12 & 144 \\
\hline 14 & Hairul Izam Febrianto & 210 & 260 & 50 & 2500 \\
\hline 15 & M. Paozan aziban & 155 & 173 & 18 & 324 \\
\hline 16 & Wahyu Ilham Jayadi & 101 & 127 & 26 & 676 \\
\hline 17 & Eliza Mazlin & 82 & 94 & 12 & 144 \\
\hline 18 & Nurhayani & 77 & 94 & 17 & 289 \\
\hline 19 & Lina Soraya & 62 & 77 & 15 & 225 \\
\hline 20 & Lovi Herayanti & 19 & 24 & 5 & 25 \\
\hline & & $\mathbf{3 0 6 1}$ & $\mathbf{3 3 7 0}$ & $\sum \mathbf{D}=\mathbf{3 0 9}$ & $\sum \mathbf{D}^{2}=\mathbf{6 6}$ \\
\hline & & & & & \\
\hline
\end{tabular}

Keterangan :

$\mathrm{XI}=$ Nilai pre test $($ tes awal) lari sprint 100 meter

$\mathrm{XII}=$ Nilai post-test (tes akhir) lari sprint 100 meter

$\mathrm{D}=$ selisih antar post test dan pret test 
2. Memasukkan data kedalam rumus

$$
\begin{aligned}
& \text { Diketahui: } \begin{aligned}
\sum d & =309 \\
N & =20
\end{aligned} \\
& t=\frac{\sum \mathrm{D}^{2}}{\sqrt{\frac{N \sum \mathrm{D}^{2}-\left(\sum \mathrm{D}\right)^{2}}{\mathrm{~N}-1}}}=6671 \\
& t=\frac{309}{\sqrt{\frac{20.6671-(309)^{2}}{20-1}}} \\
& t=\frac{309}{\sqrt{\frac{133420-95481}{19}}} \\
& t=\frac{309}{\sqrt{\frac{37939}{19}}} \\
& t=\frac{309}{\sqrt{1996,789}} \\
& t=\frac{309}{44,685}=6,915
\end{aligned}
$$

\section{Menguji nilai " $t$ "}

Berdasarkan hasil perhitungan di atas, diproleh nilai t-hitung adalah sebesar 6,915, kemudian melihat nilai t-tabel pada taraf signifikan 5\% dengan daya beda $(\mathrm{db})=\mathrm{N}-1$ (20-1=19) adalah 2,093. Kenyataan ini menunjukkan bahwa nilai t-hitung > t-tabel yaitu 6,915> 2,093 pada taraf signifikan 5\%. maka dapat disimpulkan bahwa hipotesis nol (Ho) yang berbunyi “ Tidak Ada Pengaruh Latihan Run Through Rest Ratio 1:5 Dan Latihan Run Through Rest Ratio 1:8 Terhadap Prestasi Lari Sprint 100 Meter Pada Siswa SMP Islam Montong Kubur Tahun Pelajaran 2016/2017" ditolak dan hipotesis alternative (Ha) yang berbunyi "Ada Pengaruh Latihan Run Through Rest Ratio 1:5 Dan Latihan Run Through Rest Ratio 1:8 Terhadap Prestasi Lari Sprint 100 Meter Pada Siswa SMP Islam Montong Kubur Tahun Pelajaran 2016/2017”

\section{diterima.}

\section{PEMBAHASAN}

Berdasarkan hasil pengolahan dan analisis data terhadap hasil penelitian dengan menggunakan analisis t-test terhadap hipotesis yang diajukan dalam penelitian ini ternyata teruji kebenarannya. Temuan-temuan dalam penelitian ini seperti yang dikemukakan di atas merupakan hasil analisis secara statistic yang akan peneliti kaji lebih lanjut.

Sesuai dengan hasil analisis dan pengujian hipotesis yaitu latihan run through rest ratio 1:5 dan latihan Run through rest ratio 1:8 secara signifikan dapat meningkatkan prestasi lari sprint 100 meter pada Siswa SMP Islam Montong Kubur Tahun Pelajaran 2016/2017, yang dimana hasil pengujian hipotesis diterima kebenarannya. Hal ini berarti bahwa ada pengaruh latihan run through rest ratio 1:5 dan latihan Run through rest ratio 1:8 terhadap prestasi lari sprint 100 meter pada siswa SMP Islam Montong Kubur Tahun Pelajaran 2016/2017.

\section{SIMPULAN}

Berdasarkan hasil pengujian dan analisa data maka dapat disimpulkan bahwa: Ada pengaruh latihan run through Rest Ratio 1:5 dan latihan run through Rest Ratio 1:8 terhadap prestasi lari sprint 100 meter pada siswa SMP Islam Montong Kubur Tahun Pelajaran 2016/2017

\section{SARAN}

Dari hasil penelitian ini, maka penulis akan mengemukakan beberapa saran dengan harapan akan ditindak lanjuti sehingga perkembangan dan prestasi lari sprint 100 meter bisa lebih meningkat, adapun saran bagi semua pihak yaitu :

a. Pemerintah

Kepada pemerintah diharapakan untuk lebih memberikan ruang dan perhatian serta material kepada para mahasiswa yang sedang atau ingin melaksanakan penelitian agar peroses penelitian berjalan lancar.

b. Kepada pelatih dan guru olahraga

Diharapkan agar mampu memotivasi para atlet- atletnya dalam meningkatkan prestasi-prestasi dalam cabang olahraga lari sprint 100 meter dan memberikan latihan yang bervariasi seperti latihan run through dan latihan yang lainnya agar atlet tidak cepat merasa bosan.

c. Kepada siswa

Diharapkan melakukan latihan run through untuk meningkatkan kecepatan dalam berlari dan lebih semangat dalam latihan lari sprint 100 meter, sehingga 
mampu meningkatkan rasa percaya diri dan meningkatkan kemampuan teknik dan taktik pada tiap individu dalam dalam cabang olahraga lari sprint 100 meter

d. Kepada peneliti lain

Agar melakukan penelitian yang lebih mendalam dan akurat tentang efektivitas dalam setiap model variasi latihan run through dan lain sebagainya terhadap peningkatan kecepatan dalam lari sprint 100 meter

\section{DAFTAR PUSTAKA}

Aip,Syarifuddin,. 1992. Atletik, Jakarta : Depdikbud Dirjen Dikti

Arikunto, Suharsimi. (2013). Prosedur Penelitian. Jakarta : Rineka Cipta.

IKIP Mataram, 2011 buku pedoman penulisan karya ilmiah :Mataram

Maksum, Ali. 2009. Metode Penelitian dalam Olahraga. Surabaya

Nala, Ngurah, 1998. Prinsip pelatihan fisik olahraga. Tesis S2. Universitas Udayana Denpasar

Purnomo,Eddy. 2007 Pedoman Mengajar Dasar Gerak Atletik. Yogyakarta : Universitas Negeri Yogyakarta

Sugiyono, (2013). Metode Penelitian Kuantitatif Kualitatif Dan $R \quad \& \quad D$. Bandung: Penerbit Alfabet.

Sugiyono.2007. Metode Penelitian.bandung: Alfabeta. 